Accepted for publication within the

International Journal of Management Reviews - 23-4-2012

NOT TO BE CIRCULATED OR CITED WITHOUT PERMISSION OF THE AUTHORS

Workplace Bullying, Mobbing and General Harassment: A Review

\author{
*Dr Sara Branch \\ Research Fellow \\ Key Centre for Ethics, Law, Justice and Governance \\ Griffith University \\ Mt Gravatt campus, Mt Gravatt, Griffith University, QLD 4122, Australia \\ Telephone: +61 (0)7 37355666 \\ E-mail: s.branch@griffith.edu.au \\ Dr Sheryl Ramsay \\ Senior Lecturer \\ Griffith Business School \\ Griffith University \\ Nathan campus, Nathan, Griffith University, QLD 4111, Australia \\ Telephone: +61 (0)7 37357460 \\ E-mail: s.ramsay@griffith.edu.au \\ Professor Michelle Barker \\ Professor \\ Griffith Business School \\ Griffith University \\ Nathan campus, Nathan, Griffith University, QLD 4111, Australia \\ Telephone: +61 (0)737357952 \\ E-mail: m.barker@griffith.edu.au
}




\section{Workplace Bullying, Mobbing and General Harassment: A Review}

Research into workplace bullying has continued to grow and mature since emerging from Scandinavian investigations into school bullying in the late 1970s. Research communities now exist well beyond Scandinavia, including Europe, the United Kingdom, Australia, Asia and the United States of America. While the terms harassment and mobbing are often used to describe bullying behaviours, workplace bullying tends to be the most consistently used term throughout the research community. In the past two decades especially, researchers have made considerable advances in developing conceptual clarity, frameworks and theoretical explanations that help explain and address this very complex but often oversimplified and misunderstood phenomenon. Indeed, as a phenomenon, workplace bullying is now better understood, with reasonably consistent research findings in relation to its prevalence; its negative effects on targets, bystanders and organisational effectiveness; and some of its likely antecedents. However, as highlighted in this review, many challenges remain, particularly in relation to its theoretical foundations and efficacy of prevention and management strategies. Drawing on Affective Events Theory this review advances understanding through the development of a new conceptual model and analysis of its interrelated components, which explain the dynamic and complex nature of workplace bullying and emphasise current and future debates. Gaps in the literature and future research directions are discussed, including the vexing problem of developing an agreed definition of workplace bullying amongst the research community, the emergence of cyberbullying, the importance of bystanders in addressing the phenomenon and the use of both formal and informal approaches to prevention and intervention. 


\section{Introduction}

Workplace bullying, due to its severe personal and organisational effects, detracts from the development and maintenance of vital, diverse and productive workplaces. Interest in workplace bullying emerged over three decades ago with considerable research conducted by scholars throughout the world in the past 20 years. In this time researchers have developed a better understanding of the nature of this complex but often misunderstood phenomenon (see Wheeler et al. 2010). While different terminology exists, workplace bullying tends to be the most consistently used term, with Einarsen and colleagues (2011) recently asserting that "harassment, bullying, and mobbing" can be used interchangeably (p. 5), however, recently calls have been made to examine the differences between related concepts such as, incivility and bullying (Hershcovis 2011). With workplace bullying now acknowledged as an identifiable research area of growing interest, we felt that a critical review of academic enquiry, sourced from scholarly papers and conferences from around the world was timely. Following a brief review of the more traditional areas that have focussed on the prevalence of workplace bullying and its definition, we turn to conceptual developments and current debates that have shaped academic enquiry. From our review, we develop and present a new model that enhances understanding of the complexity of workplace bullying and provides direction for future research.

\section{Prevalence of Workplace Bullying}

Regrettably, research suggests that a significant number of people are exposed to persistent abusive treatment within the workplace (Keashly and Harvey 2006), with the majority of studies within Europe indicating between $10 \%$ and $15 \%$ of the workforce is exposed to workplace bullying (Zapf et al. 2011) with North American research reporting similar prevalence rates (Keashly and Jagatic 2011). However, depending on the definition of workplace bullying used (discussed below), its reported prevalence can vary quite 
dramatically. While some researchers define bullying as having occurred if the target has experienced bullying behaviours at least once or twice a week for 6 months (Leymann 1996), others measure a less frequent occurrence of the behaviours, sometimes with no nominated time duration (Zapf et al. 2011). This is a significant, ongoing dilemma for researchers and practitioners, for which agreed-upon resolution would be useful due to legal and policy implications (Einarsen et al. 2011; Nielsen et al. 2011).

Despite this, extensive research has occurred into those who may be most at risk of being a target of workplace bullying. The majority of the research has focused on downwards bullying (as perpetrated by managers against subordinates); to a lesser extent on horizontal bullying (one colleague bullying another); and more recently on upwards bullying (a subordinate bullying a person in a managerial position; for a review of prevalence rates see Zapf et al. 2011). Thus, bullying can occur within all levels of an organisation. Additionally, despite some possible concentration in particular industries (Hubert and van Veldhoven 2001; Zapf et al. 2011), workplace bullying can be found in most organisations and industries (Lewis and Gunn 2007).

\section{Definition of Workplace Bullying}

Perhaps due to the complexity of the phenomenon, researchers and practitioners continue to struggle to develop an agreed upon definition of workplace bullying (Saunders $e t$ al. 2007), with some researchers questioning whether a uniform definition is possible (Rayner et al. 2002). Fevre et al. (2010) recently identified a "constant tension" in locating a definition that appropriately reflects the nature of the phenomenon across a range of cultural contexts and also retains acknowledgement of the original academic work in the area (p. 75). Nevertheless, there does appear to be agreement in the academic community as to the essential characteristics that determine the phenomenon (Branch 2008; Nielsen et al. 2008). 
These elements are captured in a widely used definition, which emanated from Scandinavia and was adapted from Olweus' $(1978 ; 1993)$ research into schoolyard bullying.

"[Workplace bullying is] a situation in which one or more persons systematically and over a long period of time perceive themselves to be on the receiving end of negative treatment on the part of one or more persons, in a situation in which the person(s) exposed to the treatment has difficulty in defending themselves against this treatment" (Matthiesen and Einarsen 2007, p. 735)

In relation to the definition provided, 'period of time' firstly reflects the characteristic of persistency, or a pattern of behaviours (Einarsen et al. 2011), which distinguishes bullying from a 'one-off clash' (Saunders et al. 2007; Hoel and Cooper 2001). Thus, workplace bullying is often subject to escalation over time (Caponecchia and Wyatt 2009; Zapf and Gross 2001). However, the intensity of some one-off events, their potential for ongoing threat (Einarsen et al. 2011), and/or single incidents being repeated with different individuals (Caponecchia and Wyatt 2009) means the issue of one-off events remains subject to debate.

Secondly, 'negative treatment' relates to the occurrence and perception of significant, inappropriate, negative or unreasonable behaviours as opposed to trivial behaviours (Einarsen et al. 2011; Hoel and Cooper 2001; Saunders et al. 2007). Reaching absolute agreement on which are bullying behaviours, however, is virtually impossible because issues such as context, intensity and the existence of patterns of behaviour are important (Rayner 1997), as is a person's “subjective perception of being bullied”, which can vary quite substantially across individuals (Agervold 2007, p. 163). Thus, for researchers, practitioners and most importantly, targets of bullying, labelling specific workplace behaviours as acts of bullying is difficult. Furthermore, as technology develops, the tactics 
used by perpetrators are also likely to vary, requiring ongoing examination. For example, an Australian study that explored bullying in the manufacturing sector found that $10.7 \%$ of respondents had experienced cyberbullying (Privitera and Campbell 2009).

A target's 'difficulty in defending themselves', is the final, commonly agreed upon definitional element, which can be conceptualised as an imbalance of power between the parties. According to the definition, interactions between parties with equal power would not be labelled as workplace bullying (Einarsen et al. 2011; Hoel and Cooper 2001; Rayner et al. 2002). Importantly, a target's diminished power to defend him/herself could be due to either formal and/or informal power structures in which they work (Branch et al. 2007b; Lamertz and Aquino 2004), or to the perpetrator's continuing inappropriate, negative behaviours, which wear down the target's ability to defend him/herself (Einarsen 2000).

\section{Conceptual Development}

In order to understand a phenomenon as complex as workplace bullying, a dynamic theoretical framework is required so that organisations can ultimately prevent and/or intervene in the relevant processes. However, scholarship in the area of workplace bullying has not been grounded in a strong theory base (Einarsen 2000). Indeed, according to Wheeler et al. (2010) "we have yet to explain the phenomenon with a comprehensive theory" (p. 554). Within this section of this paper we review a number of the theoretical frameworks that have been presented in the literature prior to introducing a model we developed from a synthesis of the workplace bullying and related literature. Our model will then be used to review key elements of the workplace bullying research namely; contributing factors; onset; effects on well-being; individual and organisational responses; and continuation versus possibilities of cessation.

While the workplace bullying field has been acknowledged as largely atheoretical in its orientation, there have been notable concerted attempts to redress this situation. Hoel et al. 
(2002) argued that on the evidence available, workplace bullying could be conceptualised as a significant 'psychosocial hazard', and demonstrated its relationship to the stress literature both in terms of antecedents and outcomes for individuals and the organisation. Accordingly, Baillien and colleagues assert that, while Karasek's Job Demand Control Model (Karasek 1979) has been successfully applied to a wide range of issues, there has been little attention to social behavioural concerns such as workplace bullying (Baillien et al. 2011a; Baillien et al. 2011b). Applying Karasek’s model to workplace bullying, Baillien et al. (2011a) found significant main effects (but not interactions) for high workload and low job autonomy at Time 1 to be associated with self-identification as a target at Time 2 (as indicated by the Short-Negative Acts Questionnaire; S-NAQ). Additionally, significant interaction effects (but not main) for high workload and low job autonomy at Time 1 were associated with selfidentification as a perpetrator at Time 2 . They conclude that their research generally supports the work environment hypothesis and contributes understanding to both target and perpetrator roles. Also, the Job Demand Control Model is relevant to both explaining workplace bullying and identifying areas of prevention, including an avoidance of high strain jobs, with a focus on increased autonomy and reasonable workloads.

Another important perspective relates to the conceptualisation of workplace bullying as a particular and severe type of escalating conflict. Using the Conflict Escalation Model of Glasl (1994 as cited in Zapf and Gross 2001) and a series of quantitative and qualitative studies, Zapf and Gross found that most bullying cases could be tracked according to the escalating process described by Glasl. Escalation moves though various phases, commencing with attempts to cooperate and moving over time to increasingly higher levels of dysfunctionality. As well as individual effects, they discuss the wide range of intervention strategies and possible outcomes that reflect a similarly escalating frame throughout the bullying process (e.g. rational discussion through to departure from the workplace by the 
target), noting that preventive measures and intervention in early stages of conflict escalation are highly recommended.

One perspective which may advance the conceptualisation of workplace bullying as an escalating conflict relates to the area of hostile workplace relationships (see Aquino and Lamertz 2004; Keashly and Harvey 2006). Aquino and Lamertz (2004) in their relational model of workplace victimisation highlight the interaction between context, target and perpetrator. They assert that "a person [who] perceives himself or herself to be a [target] during one social encounter may retaliate in a later encounter, thereby enacting a perpetrator role" (Aquino and Lamertz 2004, p. 1025). Historically this perspective has been fraught with difficulty as researchers and practitioners have understandably wished to avoid 'blaming the victim.' Nonetheless, this point of view is important as it demonstrates the complexity of workplace bullying, in that identifying a 'true' target or perpetrator may not be possible in many cases (see Glomb 2002). Moreover, this relational perspective enables research from the wider field of communication to be applied to workplace bullying.

Another important perspective and central definitional element of workplace bullying is that of 'power'. Initial research in this field commonly identified managers as the perpetrators of bullying, often linking "top-down" bullying to organisational structures, including the role of overseeing others and relational power differentials, particularly the mis-use thereof (Roscigno et al. 2009, p. 1562). A target's powerlessness, in this case, results from the imbalance of power seen in the organisation hierarchy. By contrast, others propose more complex conceptualisations of the relationships between power and workplace bullying. Branch et al. (2007b) propose a power and dependency approach in explaining findings where subordinates were able to derive sufficient informal power to bully a person in a higher organisational position. Along similar lines, Lamertz and Aquino (2004) report on the "precarious position of managers" unable "to draw effectively upon their formal powers" as 
one interpretation of their finding in relation to the amount of perceived victimisation towards managers (p. 814). Indeed, the recognition of upwards (e.g., Branch et al. 2007a) and horizontal bullying (e.g., Schat et al. 2006) emphasises that processes beyond formal power are at play. That is, personal power, or power derived by a person's access to informal sources of power (e.g., expertise, information and networks of people, French and Raven 1959; Raven 1993), can be used to gain sufficient power to bully others in the workplace (Branch et al. 2007b; Hutchinson et al. 2006b).

Alternatively, in an attempt to emphasise the dynamic nature of workplace bullying, Hutchinson et al.(2006b) applied Foucault's (1977) and Clegg's (1993) conceptualisation of power. Using this approach, bullying was depicted as a dynamic and complex interaction of organisational and social structures, rather than a formal relationship or an interpersonal dispute. Using this conceptualisation, bullying is a process where implicit social and organisational rules, group membership and informal networks of personal connections are involved, thereby tapping into the informal or personal sources of power available in the workplace. Moreover, on the basis of a large qualitative study focussed on workplace mobbing, Shallcross et al. (2010) analysed a number of cases where individuals were publicly humiliated and seemingly terrorised through the tactics of gossip, rumours and false accusations of bullying. According to the authors, "power was enhanced" through the use of these tactics because "the implied threat to the recipient [was] that they too may become the target” (p. 29). Powerlessness in this case results from ongoing gossip, rumour and humiliation as a result of an accusation of bullying, with the accuser obtaining power due to the reactions that the term 'bullying' evokes. These studies highlight the perspective that “informal sources of power are not to be underestimated in their capacity to deliberately perpetrate" bullying (Shallcross et al. 2010, p. 29). 
Indeed, Branch et al. (2007a) found that a "lack of a legitimizing agent from the organization during change may result in staff perceiving the manager as lacking legitimate power” (p. 275), thereby reducing a manager's ability to influence others. Likewise, Miller (1997) in her study of gender harassment in the US Army, found that women in positions of authority were often not respected due to a perception that their power was illegitimately obtained (e.g. via a quota system). Branch et al. (2007a) also found that a lack of respect for the manager's role, as well as subordinates' advanced knowledge and skills (reflecting the subordinate's information, expert and referent power, French and Raven 1959; Raven 1993), creates a dependency on subordinates that could reduce a manager's ability to respond to inappropriate behaviour. Thus, through these explorations, the concept of power goes beyond the notion of an abuse of authority, presenting a more complex explanation of informal power processes where dependency by a manager is a key factor that can result in a power imbalance that enables the onset and escalation of bullying.

What these explorations demonstrate is that all actors in workplace bullying potentially have access to power, as seen in Lutgen-Sandvik's (2006) interview study with 30 witnesses and target-witnesses. Notwithstanding concerns about the risks involved with resisting bullying, interviewees engaged in a range of resistance strategies such as confronting the bully; using a collective voice; embracing labels like troublemaker and developing links to others as allies. Despite interviewees perceiving an escalation of abuse due to their resistance, the authors emphasise "the power-as-commodity frame presents power as something bullies 'have' and targeted workers do not...[and] overlooks circumstances in which workers resist and eventually alter organizational systems" (p. 427). Indeed, it is for this reason that many scholars within the field do not refer to targets as 'victims', which can be seen as a label that adds to a person's feeling of helplessness (Magley et al. 1999). 
In summary, despite many people within an organisation having access to various types of power that could enable bullying of another person; the initial approach to workplace bullying was to look at the manager as a bully. However, Branch et al. (2007b) warns that taking a narrow view of power risks overlooking the complex role that power plays in workplace bullying. Clearly all within the workplace have access to a range of power sources (that could be used inappropriately) and, by exploring power dynamics a more complex explanation of workplace bullying emerges. However, to date much of the literature on power and workplace bullying has been conceptual (Keashly and Jagatic 2011) with research that applies these conceptualisation restricted to only a few studies (e.g., Branch et al. 2007a; Lamertz and Aquino 2004). This theoretical area of workplace bullying has the potential to be highly informative of prevention and management strategies.

One of the most widely known and comprehensive frameworks of workplace bullying was proposed by Einarsen et al. (first introduced by Einarsen 2000; Einarsen et al. 2003; 2011), wherein societal, organisational and individual characteristics are presented as dynamic processes that can either hinder or contribute to the occurrence and continuation of workplace bullying; and result in individual and organisational reactions and effects that loop back to affect factors present in the environment. However, within this framework the group level (which represents an important structural conduit between the individual and the organisation) and the characteristics of perpetrators are not visually represented on the model, although these are both briefly discussed in the explanation, perhaps reflecting the lack of attention that currently exists in the literature in relation to the group level of analysis (see Ramsay et al. 2011) and perpetrators (see Zapf and Einarsen 2011).

Several other models have also focused on the interplay between individual and organisational elements, ultimately highlighting the importance of the interactive processes of workplace bullying within an organisational culture (e.g., Harvey et al. 2006; Heames and 
Harvey 2006). Aquino and Lamertz's (2004) model of victimisation similarly emphasises the importance of context, suggesting that certain characteristics of an organisational culture and power differences within dyads can increase "the likelihood of victimization occurring over the course of an ongoing workplace interaction" (p.1024) Recently, Parzefall and Salin (2010) argued that Social Exchange Theory can be used to highlight the importance of exchange relationships in promoting (or otherwise) a 'justice climate' within organisations. Perceptions of injustice can lead to attitudes and behaviours being adjusted downwards, which can explain the negative impact upon the work environment, including bystanders (Parzefall and Salin 2010). In essence the above models propose similar processes, characteristics of the work environment along with those of individuals play a part in the occurrence and continuation of workplace bullying, which then has effects on individuals and the workplace, feeding back to encourage or, less probably, deter further bullying.

One interesting conceptual development in the field is the exploration of emotions and in particular the application of Affective Events Theory (AET; Weiss and Cropanzano 1996). While the application of AET to the field is an important and only recent addition to the workplace bullying literature there has been wider use of the theory within the broader antisocial behaviour literature. Developed by Weiss and Cropanzano (1996), AET suggests that people often react emotionally to incidents, which influences their subsequent behaviours, attitudes and ultimately their well-being. Thus, incidents in the workplace, such as bullying, can be considered an affective event (see Ghosh et al. 2011; Glasø et al. 2011; Lee and Brotheridge 2006; Lim et al. 2008). Brotheridge and Lee (2010), in one of the few studies directly linking AET and bullying, examined the emotional reactions to specific bullying behaviours, proposing that each bullying event will produce an affective reaction. They found that belittlement, having your work undermined, and verbal abuse were all associated with the negative emotions of sadness, restlessness, anger and most often, 
confusion. Brotheridge and Lee's (2010) research also indicates that repeated negative events may sensitise targets to further negative events, thereby increasing the level of emotions experienced.

Indeed, the AET literature highlights the importance of the duration and intensity of conflict events rather than the individual events themselves (Ayoko et al. 2003). For instance, Fuller et al. (2003), using time series modelling, found that regularly experiencing low-level stressful events "has the potential to cause workers to experience gradually increasing levels of strain over time" (p. 1028). This may explain how someone in a stressful work environment who is already experiencing strain may not be able to respond effectively to bullying when it occurs, thereby beginning the negative cycle of escalating events that can lead to ongoing bullying. Lutgen-Sandvik's (2008) interview study highlights this process with targets experiencing a range of emotions beginning with low levels of discomfort and nervousness in the pre-bullying phase, moving to more extreme feelings of shame as the process continued. The ongoing destabilisation of target's self-identity, due to the escalation of bullying meant "many [targets] reported being unable to rebound fully between attacks" (p. 109). D'Cruz \& Noronha's (2010) study of 10 targets also highlights the emotional strain that on-going negative events can have,with "depression, anxiety, hopelessness and helplessness" prevailing (p. 525). This in turn resulted in decreasing positive feelings about work and people, often leading to withdrawal, and quitting the organisation considered the best or only solution. Thus, workplace bullying could be considered an affective episode consisting of a number of affective events, "where it is not so much particular events that result in outcomes, but rather the accumulation of positive or negative events in an episode that determines how we feel" (Ashkanasy 2003, p. 21) and results in detrimental outcomes for individuals (Kanner et al. 1981). This conceptualisation accords with the definition of workplace bullying presented earlier (especially in terms of persistency). 
Further highlighting the importance of emotions to the field, Grandey et al. (2007) found that verbal aggression from supervisors, co-workers and customers "all had significant and unique associations with emotional exhaustion" (p. 75). They argued that verbal abuse from customers can have a negative effect on targets who are expected to control their negative reactions, and have fewer response options. Similarly, Sliter et al. (2010) found "that customer incivility was positively related to emotional exhaustion through the perceived emotional labor demands of one's job" (p. 476). Thus, limited ability to express emotions or respond to aggressive behaviour influences emotional exhaustion, which may explain why support is so important to targets of anti-social behaviour. Indeed, one study found that positive support from colleagues as well as friends and family could counteract the accumulation of negative events (Grzywacz and Marks 2000).

Drawing on the literature reviewed above, including the recent inclusion of affective events, we present a model to both highlight and extend our current understanding of workplace bullying (see Figure 1). While this is reflective of existing frameworks in terms of the societal, organisational and individual characteristics and interactions, it also seeks to make more salient the processes of workplace bullying as depicted via individual responses, group dynamics within organisations, and the interactive and cyclical nature of interactions that ultimately lead to the label of workplace bullying. As such the model consists of seven elements; A: Society; B: the work environment, which includes characteristics of the organisation (including group characteristics), target, perpetrator and bystanders; C: the onset of affective events or bullying; D: the individual and organisational response (highlighting the dyadic interaction between perpetrator and target, as well as relevant groups); E: individual and organisational well-being; F: the possible continuation of affective events; and G: the possible cessation of affective events. Importantly we believe this model highlights and contributes to current understanding of the processes involved in workplace bullying and 
makes important additions in terms its dynamic and cyclical nature, which assists in the identification of intervention points that may minimise its occurrence. Each of the elements in the model will now be reviewed, highlighting potential areas for future research.

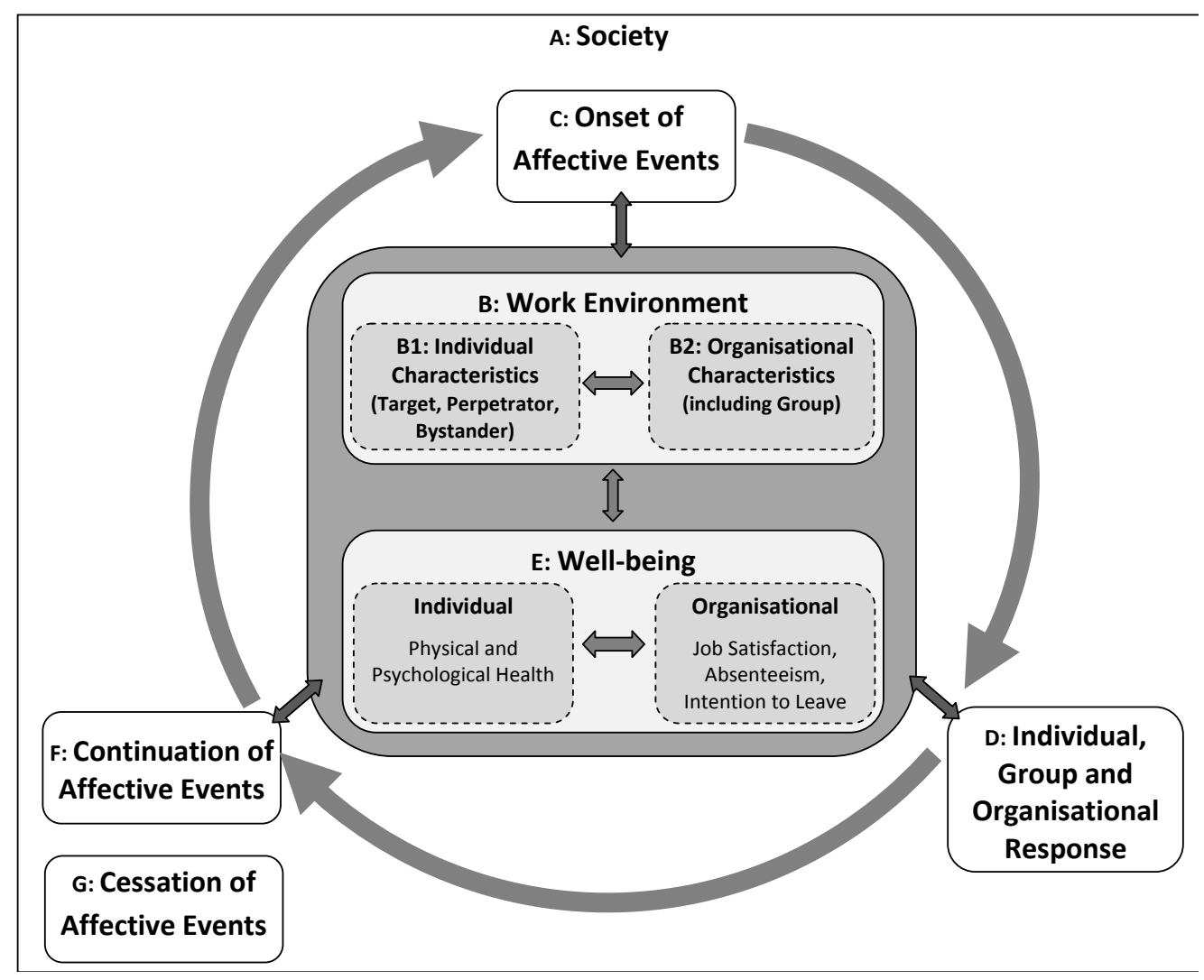

Figure 1. Cyclical Framework of Workplace Bullying

\section{Society (A)}

While it is recognised that society can influence bullying in the workplace, very little is known about how this occurs (Einarsen et al. 2011). Nevertheless, Einarsen and colleagues state that bullying needs to be viewed against the background of societal elements such as culture, legal context and socio-economic factors (as acknowledged in their framework). Most references to society in the literature centre on how the rate of change in today's society can influence the occurrence of bullying (Einarsen et al. 2011); how workplace bullying can potentially affect society due to the costs associated with the phenomenon (e.g., Coyne et al. 
2000; Leymann 1996; Salin 2003b) and how pressures in society can bring about change to recognise and address bullying (Namie 2003).

Recently, Beale and Hoel (2011) argued that workplace bullying may be reinforced by the very nature of the "capitalist employment relationship" (p. 5), which in essence seeks to control employees through hierarchical structures. In some cases, this can be linked to negative downward pressures to gain compliance and increased productivity, perhaps promoting a 'climate of fear' (Rayner 1999). Beale and Hoel (2011) argue that employers and managers may not fully support anti-bullying intervention initiatives, which essentially seek to redress power imbalances in the workplace and therefore interfere with the status quo.

Another perspective in the workplace bullying literature is the possibility of broad differences based on national culture. While the cross-cultural perspective presents a complex area that is difficult to research, one recent study has investigated perceptual differences of workplace bullying in two world regions (Central America - Costa Rica and Southern Europe - Spain, Escartín et al. 2011). Whereas there were many similarities in the understanding of workplace bullying, employees from Central America placed more emphasis on the physical component of bullying, compared to their European counterparts. Further research is needed into this level of our understanding of workplace bullying.

\section{Work Environment (B): Interaction between Individual and Organisational Characteristics (including groups)}

Even though there are overlaps and complex interrelationships among the antecedents of workplace bullying, they can be largely viewed as individual, interpersonal, group and organisational factors (see Einarsen et al. 2011). Indeed, the literature increasingly portrays workplace bullying as a multi-faceted phenomenon, with its antecedents integrally related to interactions between characteristics of individuals such as the perpetrator/s and target/s (see B1 in model) and the organisational environment (see B2 in model; Harvey et al. 2006; 
Heames and Harvey 2006; Salin and Hoel 2011; Zapf 1999). Baillien et al. 's (2009) and Salin's (2003b) research especially emphases this interaction. Within Baillien et al. 's (2009) global model of antecedents, three pathways are identified; bullying due to "intrapersonal frustrations ('strains')" (such as dissatisfaction with recent changes), the closely related conflict escalation of either personal or work related conflicts and "explicit or implicit stimulation through team and organizational characteristics (intragroup aspect)" such as a climate that accepts gossip or backbiting (p. 7). In addition, within this study, individual and organisational characteristics were found to influence each of these pathways by either being "the basis for frustrations, conflict and direct encouragement of bullying" or affecting how well an individual is able to manage the conflict or frustrations (p. 10).

Similarly, Salin (2003b) identified three classifications for explanations of bullying which often interact with each other. First, she identified enabling structures including elements necessary to the occurrence of workplace bullying such as a power imbalance, a perception of low costs to the perpetrator for their behaviour, dissatisfaction and frustration. Second, motivating structures are the characteristics of the environment that encourage bullying, including competition for jobs and an organisational culture that rewards aggressive or bullying behaviour. Indeed, research suggests that job insecurity (see De Cuyper et al. 2009); organisational change resulting in role conflict and job insecurity (see Baillien and De Witte 2009); a stressful work environment (see Hauge et al. 2009); “poorer psychosocial work environments" (see Agervold 2009, p. 274); high workloads, workgroup disharmony and acceptance of inappropriate behaviours (see Branch et al. 2007a); high job ambiguity and job complexity as well as low autonomy (Baillien et al. 2009) are associated with workplace bullying. Third, Salin identified precipitating processes that trigger bullying, such as a restructure or other forms of organisational change. 
While the above reflects the importance of the work environment in workplace bullying processes, historically, most researchers initially focused on the individual factors that may precipitate occurrences of workplace bullying. Indeed, according to Zapf and Einarsen (2011), the study of workplace bullying would be incomplete without consideration of the various personality and individual attributes related to targets and perpetrators. In a recent study however, Lind et al. (2009) concluded that differences in personality were too minimal to be able to "differentiate targets of workplace bullying from nontargets", indicating that explanations of workplace bullying that only refer to singular explanations, such as personality, are inappropriate (p. 231). Nevertheless, some findings have been noted with regard to contributing individual factors related to either the target or perpetrator, such as personality traits. Identified personality traits of targets include being relatively more introverted, anxious, conscientious, neurotic, submissive (Coyne et al. 2000), less agreeable (Glasø et al. 2007) and low self-esteem (Matthiesen and Einarsen 2007). These characteristics may well be linked to reportedly lower social competencies and could make targets vulnerable to bullying (Zapf and Einarsen 2011). Alternatively, characteristics, such as conscientiousness, could contribute to the behaviour of targets clashing with prevailing group norms (e.g., putting in more effort or following rules more closely than the group, see Ramsay et al. 2011; Salin 2003a). However, contradictory findings with regards to personality persist. What is clear is that due to the complexity of the phenomon, a singular portrait of a target does not exist (Glasø et al. 2007; Zapf and Einarsen 2011).

Notably, much more is known about targets than perpetrators, the latter perhaps being more reluctant to come forward (Zapf and Einarsen 2011). However, the literature does suggest that perpetrators may bully due to a need to protect their self-esteem (Baumeister $e t$ al. 1996) and/or because of a lack of social competencies, such as emotional control and perspective taking (Zapf and Einarsen 2011). Indeed, Baillien et al. (2009) identified nine 
characteristics of perpetrators, such as "intolerant and being very strict" which may suggest an inability to accommodate and adopt flexible attitudes and behaviours (p. 9).

Keashly and Harvey (2006) also highlight the interaction between actors in the escalation of workplace bullying with "prolonged exposure to abuse [resulting] in the target behaving in a hostile and aggressive manner" (p. 98). Indeed an understanding of workplace bullying must include the reciprocal nature of communication, with research (e.g., Zapf and Gross 2001) indicating that the reactions of targets may play a part in workplace bullying experiences (see Aquino and Lamertz 2004 for a relational model of workplace victimisation). As highlighted previously, the target-perpetrator relationship is complex, with an accusation of bullying linked "to a series of interactions that are built up over a period of time" (Tehrani 2003, p. 280). According to Tehrani (2003), as relationships become more negative and stressed, seemingly small issues (e.g. not saying hello in the morning) can be interpreted as an aggressive act. As a result, the communication literature may be useful in understanding the deterioration of workplace relationships to the point they become hostile. Additionally, this perspective highlights potential interventions that can promote the use of effective communication skills that may be valuable in de-escalating bullying processes (see Hess 2000; 2006).

While these interpersonal communicative processes are clearly important, with individual and environmental perspectives the focus of significant research, group characteristics have only recently begun to be expanded (see Ramsay et al. 2011). The literature indicates that group-based differences sometimes appear to be the only reason people are bullied (e.g., minority groups who have race and ethnicity as 'visible makers' are likely to be more vulnerable, see Cortina 2008; Fox and Stallworth 2005; Lewis and Gunn 2007; Roscigno et al. 2009). More broadly, Roscigno et al. (2009) found that groups occupying structural positions associated with little power (which are also more likely to be 
linked with minority groups) were at greater risk of being bullied. In addition, the intra-group perspective has been considered by researchers. In a study of diverse teams in large organisations, it was found that communication openness, defined as the ease of talking and extent of understanding within the group, was important, with low levels of communication openness associated with higher levels of destructive reactions to conflict, bullying behaviours and emotional reactions to bullying (Ayoko 2007).

While these teams are part of the formal structure (Ayoko 2007), informal groups have also been considered, with certain groups seen as strategic players in bullying processes. Accordingly, Hutchinson et al. 's (2006a) qualitative research within hospitals identified powerful informal networks among perpetrators of workplace bullying. Their findings suggest that strong social, cooperative relationships contributed to "the continuation and proliferation of workplace bullying" (p. 246). They found that legitimate organisational processes (e.g. promotion) were used to help conceal bullying and simultaneously allow it to flourish. Similarly, Salin (2003a) demonstrated that bullies could be rewarded through overt processes such as performance review and promotion. Alternatively, from the targets' perspective, Lutgen-Sandvik (2006) found that targets were sometimes able to turn to each other and to sympathetic co-workers for support and seek to increase their power base through a collective voice and coordinated, group-based resistance measures. Importantly, the role of groups and bystanders in contributing to, or tacitly supporting, workplace bullying is still largely unclear and is another vital area for future research (Keashly and Jagatic 2011). In a recent paper, Namie and Lutgen-Sandvik (2010) emphasised the role that upper management, HR, and colleagues, can play by either overtly joining in or passively supporting the bullying through inaction. Overall, this section highlights the importance of interactions between individuals and their environment, including groups, in workplace bullying processes. However, the future research agenda needs to focus on further delineation 
of such interactions, with regards to the role of formal and informal groupings, targets and perpetrators.

\section{Onset of Affective Events (C)}

As highlighted earlier, a range of factors can result in the onset of affective events with particular triggers like conflict escalation (Baillien et al. 2009) and organisational change (Branch et al. 2007a; Salin 2003b) identified. Additional research also points to the value of AET in understanding the onset of workplace bullying. For instance, one study found that emotional reactions to workplace bullying predicted counterproductive behaviours (e.g., sabotage by deliberately doing your job incorrectly, Ayoko et al. 2003). Similarly, negative emotions were found to be an antecedent to incivility (Reio and Ghosh 2009). Ghosh et al. (2011) in their application of AET in the mentor-protégé relationship found that "distancing behaviour by mentors can be an affective event that elicits negative emotions in protégés that then prompt them to instigate incivility against their mentors (e.g., affect-driven behaviour)" (p. 33). Thus, the reactions of others can influence the escalation of inappropriate behaviours, possibly leading to workplace bullying (see Zapf and Gross 2001).

\section{Individual and Organisational Responses (D)}

Although the dual themes of prevention and management of workplace bullying are emphasised repeatedly within the literature, understanding the processes of how best to move from conceptualisation to good practice is only starting to gain momentum. While the literature does reveal agreement about the complexity of the problem and the associated need for multi-faceted approaches to dealing with it, comprehensive solutions remain elusive (Saam 2010). This is perhaps best reflected in Hoel and Einarsen's (2010) quantitative results of statutory regulations enacted in Sweden in 1993. While bullying in Sweden has increased since the legislation was introduced, perhaps because of greater awareness of the problem and its characteristics (which is positive), a number of shortcomings were identified in the 
enactment of the legislation, especially in the appropriate training of those required to provide help to targets. As a result, we are cautioned against relying on a narrow, legislative framework to regulate a complex problem; particularly without appropriate prevention efforts, interventions and rehabilitation processes throughout the organisation and specific training for all stakeholders, including management, employees and trade union representatives (Hoel and Einarsen 2010). Similarly, at the organisational level, formal written policies and regulations should be accompanied by training and development initiatives that are integral to addressing workplace bullying. Also required is a positive influence perspective provided by a supportive environmental framework (e.g. skilled leadership), as suggested by research into AET (see Grzywacz and Marks 2000), and the associated goal of increasing positive norms of behaviour in the workplace (see Keashly and Neuman 2009; Osatuke et al. 2009; Ramsay et al. 2011). These elements will now be explored.

La Van and Martin's (2008) “managerial intervention matrix” (p. 154) highlights the possibility of using both formal and informal prevention and management strategies. First, in terms of antecedents, the matrix indicates there could be systematic, formal investigations into triggers of workplace bullying and areas of vulnerability but, informally, there needs to be awareness of unconscious signals about tolerance (or lack thereof) of bullying that could be enough to help precipitate or hinder bullying. One promising intervention in this regard is the Civility, Respect and Engagement in the Workplace (CREW) initiative, which seeks to develop a work environment defined by civility, thereby aiming to reduce acceptance of inappropriate behaviours in the workplace (see Osatuke et al. 2009).

Second, in relation to behaviours, there could be formal incident reports but this should be augmented by a focus on more informal modelling of appropriate behaviours by as many people as possible in the organisation. Research by Keashly and Neuman (2009) which 
involved the design of an intervention that included modelling of collaborative and respectful communication (along with other elements) as a way to change organisational members' communication styles and reduce aggression, reflects one such approach which "can become embedded in the organization's culture" (p. 355). Third, consequences (i.e., formal policies, procedures, and processes around codes of conduct, discipline, and grievances) could be set out, while informally, there needs to be conscious or unconscious reinforcement of appropriate behaviours (e.g. giving appropriate feedback). Thus, the combination of formal (e.g., Employee Assistance Programs, mental health and legal support; see Shannon et al. 2007 for a study into the use of these services) and informal efforts, which develop positive norms and a well-trained workforce that understands and models appropriate communication styles, could reduce the likelihood of negative behaviours occurring.

Moreover, Saam's (2010) study with 18 consultants with experience in resolving cases of workplace bullying signals the potential value of coaching (e.g. providing coaches to assist parties to resolve the conflict, see Fox and Stallworth 2009) and organisational development (e.g. antecedents such as stress, role and leadership issues could be addressed). Consultants who preferred coaching and organisational development (rather than mediation as identified by others) viewed bullying as a contextually based interpersonal conflict that required multiple approaches to address it. Mediation was also identified as another commonly used response, however, research into the appropriateness of mediation, due to power differences in workplace bullying cases, is required (Jenkins 2011; Saam 2010).

Of the approaches proposed and used to address workplace bullying, two of the most common approaches are ‘No Bullying' policies and training. Salin's (2008) research into the perspectives and recommendations of Human Resource (HR) practitioners indicates support for written 'No Bullying' policies that make a "commitment to a bullying-free environment", define associated behaviours and consequences, identify contact persons, and outline formal 
and informal complaints and investigation processes (p. 223). However, there is debate about the value of written policies. For instance, in another study, Salin (2009) investigated organisational responses to workplace harassment by analysing questionnaire data from personnel/HR managers in Finland. None of the identified response strategies to harassment/bullying, which involved measures relating to reconciliation, punishment, transfer and avoidance as reported to the personnel/HRs manager, were significantly correlated with the possession of written anti-harassment policies. Longitudinal data is needed to establish the real value of the development of written policies and associated preventive and management measures (Salin 2008).

Interestingly, Salin (2008) found in her analysis of formal anti-bullying policies that targets of bullying were typically advised to contact their immediate superiors, suggesting that HR Departments are responsible for formulating policy and procedures, rather than any real involvement in addressing the issue. Indeed, the experiences of participants in D'Cruz \& Noronha's (2010) research would support this. When participants in their study contacted HR managers in the hope of a resolution to workplace bullying they often had to follow up their requests for action, despite initial reassurances that something would be done. In addition, participants experienced disbelief or blame, as well as cancelled meetings without notice, from the HR managers. In some cases, the alleged bully was included in meetings with HR managers, which was perceived by targets in the study as providing tacit or direct support to the alleged bully. Importantly participants reported an increase in the bullying when they began to "actively [pursue] the matter with HR" (p. 525).

Recently, Rayner and Lewis (2011) described the critical role HR plays in managing incidents of workplace bullying, recommending that HR departments take a health and safety approach to workplace bullying, with bullying perceived as a risk to be addressed as quickly as possible. By contrast, "most HR departments take a 'complaints policy' route, where one 
can act only if a written complaint is received and the complainant is willing for the accused to know details of the problem", essentially reducing the possibility of informal measures (Rayner and Lewis 2011, p. 334). Interestingly, it was informal measures, such as support from colleagues, that participants in D'Cruz \& Noronha's (2010) study and others have found to be most helpful to targets. As such, in addition to an anti-bullying policy that takes a health and safety approach, awareness training strategies that include knowledge of responsibilities and obligations of employers and employees, effective risk identification processes and a system for complaints are highly recommended (McCarthy et al. 2002). Thus, a 'No Bullying' policy is perhaps most successful if used in conjunction with other efforts, such as training.

Training about the nature of bullying, support mechanisms within and outside the organisation, and the management of bullying cases (McCarthy et al. 2002; Vartia et al. 2003) have been suggested. For example, McCarthy et al. (2002) advise managers to use a 'no blame' or problem-solving strategy, as opposed to punitive measures, when approaching perpetrators. Also, training in interpersonal skills, conflict resolution and stress management have been found to assist targets to manage bullying behaviours better (see McCarthy et al. 1995). Such skills may well contribute to a target's ability to develop the resilience needed to manage such behaviour (McCarthy et al. 2002) and possibly deescalate instances. Zapf and Gross' (2001) research demonstrates that "successful [targets]" (as opposed to "unsuccessful [targets]") were able to avoid direct confrontation and inadequate passive strategies (e.g., drug use or absenteeism), and also recognise and avoid escalating behaviours (p. 515). Indeed, one recent study applying AET to workplace bullying, found that the emotional reactions of targets partly mediated the relationship between workplace bullying, and job satisfaction and intention to leave (Glasø et al. 2011), emphasing the importance of emotional skills training. 
In addition to awareness building and skills training for potential targets, training is also recommended for bystanders. The rationale for this training is that inaction by bystanders leads to perceptions of tacit support for the perpetrator. Thus, bystanders play a vital role in addressing and managing bullying behaviour (Namie and Lutgen-Sandvik 2010). One such approach is the Mentors in Violence Program (MVP, Katz 1995). Developed in the early 1990s in the USA and designed initially to challenge preconceived views of violence directed at women, this program has since been expanded to challenge perceptions of other types of violence, including bullying. The MVP program was one of the first to focus on bystanders, seeking to educate, engage and skill them to address violence (Katz 1995). More recent adaptations of this program have found long-term, positive benefits, with improvements in attitudes, knowledge and behaviour (for information see Banyard et al. 2007; Banyard et al. 2004; Katz 1995). A related approach from Canada is the Anti-discrimination Response Training (ART) program (Ishiyama in press) which uses an active witnessing model. The ART approach uses a skills training format to enhance readiness to respond to racist situations cognitively and behaviourally, and to empower otherwise passive and silent bystanders to become more active and vocal. While the program is currently used in skilling Canadian teachers and youth workers, the authors are examining how the ART model can be adapted for skills training to prevent and respond to workplace bullying.

Training programs such as MVP, ART and general skill development programs expose potential targets and bystanders to the knowledge and skills that will assist them to respond, manage and deescalate situations involving bullying. Further, these programs offer strategies to those entrusted with the important role of supporting involved parties when they need it and developing preventive policies and practices to safeguard against bullying at work (McCarthy and Mayhew 2004). Indeed, good levels of support at work were associated with lower levels of depression, lower intention to leave and higher job satisfaction scores among 
nurses who reported an experience of being bullied, compared with those who received poor levels of support (Quine 1999). Djurkovic et al. (2008) found similar results when they explored the relationship between perceived organizational support (POS), workplace bullying and intention to leave. In this study, high levels of POS were found to "offset the effects of workplace bullying on intention to leave" (Djurkovic et al., 2008, p. 415). Moreover, a lack of support may impede an individual's ability to manage bullying behaviours (Lewis and Orford 2005; Leymann and Gustafsson 1996; Matthiesen et al. 2003). These results point to the importance of support, indicating it may act as a buffer, thereby assisting targets to positively manage the experience of being bullied. Furthermore, recent work into gender and the role of personal perceptions and attributions about bullying behaviours highlights the need for skills training within the context of bullying, especially for those expected to support involved parties (see Salin 2011).

While features of support could be experienced within the broad organizational culture and specific communicative experiences, it is important to note that the seeking of support often requires a proactive approach. Should targets be feeling helpless and victimised, they may be unlikely to engage in support-seeking behaviours. In addition, concern about how seeking support may be perceived by others (Lee 1997), feelings of profound shame, as found in a study of college and university lecturers who had experienced workplace bullying (Lewis 2004), and concern about the ability of the organisation to respond effectively (Ferris 2004; Hoel and Cooper 2000) may further prevent someone from seeking support. This again stresses the importance of developing comprehensive strategies for addressing workplace bullying, including addressing the climate and culture within a workplace.

\section{Individual and Organisational Well-being (E)}

While the negative consequences of workplace bullying for targets, witnesses and organisations have been well-established (see Hogh et al. 2011 for a comprehensive review), 
an alternative perspective of well-being is beginning to emerge within the literature. Research by D'Cruz (2010) and D'Cruz and Noronha (2012) found that participants saw the need to process and understand their workplace bullying experiences in relation to their long-term well-being, with some even ultimately considering themselves "privileged to go through such an experience as it helped them discover and develop themselves without compromising their values" (D'Cruz and Noronha 2012, p. 20). The authors concluded that the emphasis participants placed on enhancing their well-being indicates an alternative approach to workplace bullying, with the potential for transformational growth despite negative circumstances (D'Cruz 2010; D'Cruz and Noronha 2012). This view accords with researchers within the stress and strain field (see Folkman and Moskowitz 2000). Despite this emerging and legitimate view that promotes a long term perspective for individuals, the immediate outcomes for targets, witnesses and organisations are overwhelming negative. For instance, Mikkelsen and Einarsen (2002) in their study of 118 targets of workplace bullying found that $80.5 \%$ of participants reported that "no other event in their life affected them more negatively than the bullying" (p. 98), despite this group also experiencing accidents, divorce, bereavement and serious illness. Likewise, another study concluded that targets of workplace bullying can experience the same level of emotional trauma as targets of assaults (Mayhew et al. 2004).

Workplace bullying has been identified as a risk factor in clinical depression (Niedhammer et al. 2006), suicide attempts (O' Moore et al. 1998), clinical levels of anxiety (Quine 1999), post-traumatic stress disorder (PTSD; Matthiesen and Einarsen 2004; Mikkelsen and Einarsen 2002; Tehrani 2004), as well as higher levels of job induced stress, intention to leave, sick leave, absenteeism, and lower levels of job satisfaction (see de Wet 2010; Kivimaki et al. 2000; Quine 1999). These individual and associated organisational effects are not confined to targets, with findings that witnesses of workplace bullying can be 
affected almost as severely as the actual target (Mayhew et al. 2004; Niedhammer et al. 2006; Rayner 1999).

Thus, workplace bullying has negative effects on witnesses as well as targets, resulting in some cases in the creation of an abusive work environment, which ultimately affects an organisation's ability to function optimally, through loss of productivity, an increase in absenteeism and intention to leave, as well as the cost of intervention programs (Einarsen 2000; McCarthy and Barker 2000; McCarthy et al. 1995). Such outcomes have vital implications for the well-being and productivity of individuals and organisations (Mayhew et al. 2004), and are likely to result in staggering financial costs to organisations (see Hoel et al. 2011 for review; Sheehan et al. 2001). Thus, the literature is clear that workplace bullying has severe effects on those who experience it directly, as well as those who witness it and organisations as a whole.

\section{Continuation of Affective Events (F)}

Perhaps one of the best known models describing the development of workplace bullying is Leymann's (1996) model, in which he suggested that bullying progresses through four stages, the conflict (stage one) that triggers the bullying (stage two), personnel management (stage three) and expulsion (stage four). Another model explaining the process of bullying was proposed by Bjorkvist (1992 as cited in Einarsen 2000; Zapf and Gross 2001). In this three phase model an increase in intensity of behaviour is the focus. In the first phase, covert behaviours such as 'white-anting' or gossip are used, while in the next phase more overt aggressive behaviours occur. In the final phase, the target experiences an intensification of both covert and overt behaviours. Thus, within the first phase the behaviours may only occur once in a while (as best as targets can tell at this stage), however, by the final phase they may be occurring daily. The escalating nature of bullying is best demonstrated in D'Cruz \& Noronha (2010) study of the experiences of 10 targets. Believing 
the bullying behaviour to be a result of a demanding work environment, targets often focused on their work. However, with the intensification of the behaviours they had to resolve why they were experiencing this behaviour while others were not. As the behaviour continued, targets' emotions oscillated between a need for reassurance and distress, with distress triumphing due to the ongoing nature of the behaviours. Support did help some targets to cope, although isolation from colleagues was identified over time for some participants. Eventually targets came to the decision to leave the organisation, which offered them some relief.

Thus, workplace bullying is considered to be a form of conflict escalation (Zapf and Gross 2001), however, perhaps due to the focus on antecedents, the processes that lead to the escalation of workplace bullying have often been overlooked (Keashly and Jagatic 2011). Glasø et al. 's (2011) application of AET to workplace bullying provides us with insight into this process with "a vicious circle of events" described where emotional reactions result in the "use of maladaptive coping strategies" (pp. 203-204). Thus, in order to assist in the development of effective interventions, further research into the life cycle of workplace bullying is required.

\section{Cessation of Affective Events (G)}

Similarly, little is known about the cessation of bullying, other than that in most cases targets eventually leave the organisation (Hoel et al. 2011). However, as highlighted in the D’Cruz \& Noronha (2010) study, exiting is often not an easy process. While targets felt "they had regained control over their lives...they felt that they had been overpowered and were incapable of successfully fighting injustice" (D'Cruz and Noronha 2010, p. 529). Often the post-bullying phase represents a painful grieving period wherein targets try to rebuild themselves, including "dealing with the perceived loss of professional reputation, organizational identity and self-confidence, and the long-term loss of core beliefs in justice or 
fairness", often developing new cynical views of the world, with many seeking therapeutic help and, for some, taking months and years to recover (Lutgen-Sandvik 2008, p. 110). Further research into the processes involved in the cessation of bullying, including cases where resolutions to bullying were found, is especially needed in order to assist in the development of suitable individual and organisational responses.

\section{Conclusion and Future Directions}

The purpose of this review was to articulate the state of knowledge in the workplace bullying field by examining frameworks, research findings and approaches, and to develop a model that both synthesises and provides guidance for future research. Despite considerable advancements in recent decades, there is still much that requires our attention, especially the key aspects of the definition itself; the development of a guiding theory; investigation of the impacts of various workplace levels and structures such as groups; and the efficacy of interventions. As such, the review indicates four significant areas for future research in the workplace bullying area.

Firstly, an agreed upon definition is required so that researchers and practitioners can work from a shared base especially in regards to formulation of workplace policies, intervention and prevention strategies, and legislative frameworks (Nielsen et al. 2011). To add to the current knowledge in the area it is recommended that key definitional dilemmas noted in the review are explored. The use of both qualitative and quantitative methods that investigate the experiences of targets, perpetrators and bystanders in relation to these issues (e.g., the possible importance of one-off acts) would be beneficial (see Hershcovis 2011 for guidance in relation to this). These approaches would help in reaching a shared understanding of the definition, including the vexed question of power sources and their distribution. Clarification in this area is especially important when considering appropriate management 
and workplace interventions, as is agreement on the research criteria of what constitutes bullying in the workplace.

Secondly, although a range of frameworks have been proposed to explain workplace bullying, some scholars suggest that a comprehensive theory in relation to the phenomenon is still lacking (Wheeler et al. 2010), the development of which forms a rich area for future research and one that has significant consequences for prevention and management. As indicated in the review, one recent advancement within the field is the application of Affective Events Theory (AET), which highlights the affective dimensions of workplace bullying and offers insight into the processes involved, such as interactions between target and perpetrator, its escalation, and how the accumulation of bullying events can lead to increasingly negative outcomes for targets, bystanders and the organisation (see Glas $\varnothing$ et al. 2011; Lee and Brotheridge 2006). This is an exciting advancement in the field and may offer the beginnings of a comprehensive theory of workplace bullying.

Furthermore, we believe that emotions focused research has the potential to significantly advance our understanding of workplace bullying. Indeed, the model introduced in this review brings in elements of AET and highlights the dynamic, complex and cyclical nature of the phenomenon. As such, the model makes a significant contribution to the field and has the potential to assist practitioners to understand likely points of intervention, as well as providing researchers with a framework by which to comprehend the rapidly growing literature in the field.

In addition, the model introduced in this paper especially highlights the lack of research into the life-cycle of workplace bullying. While a considerable amount of knowledge has been developed with regard to antecedents of workplace bullying, very little is known about how and why bullying in the workplace continues. While recent research that applied AET to workplace bullying has helped in providing an understanding of the "vicious circle of events" 
and "maladaptive coping strategies" involved in bullying (see Glasø et al. 2011, pp. 203204), further research is needed. Additional research into the deterioration of workplace relationships and escalation of conflicts that contribute to workplace bullying cases has the potential to highlight various roles and processes involved in bullying, while also informing approaches to interventions, such as the use of effective communication skills within the workplace. Thus, literature from the communication and emotions fields has the potential to assist us significantly in this regard. Similarly, little is known about the cessation of workplace bullying (apart from resignations by targets). Explorations of cases where satisfactory resolutions have resulted for all parties involved are especially needed to enable us to better understand what promotes the cessation of bullying. Further data from the perspectives of relevant stakeholders such as targets, perpetrators, supervisors, work groups, colleagues, bystanders, and HR practitioners will help us understand how to resolve bullying in the workplace successfully. Conversely, case studies involving unsatisfactory resolutions from the perspective of one or more stakeholders would also make contributions to theorybuilding and human resource management applications. Research into the life-cycle of bullying, therefore, is especially needed to facilitate the development and critical review of suitable individual and organisational responses.

Thirdly, although workplace bullying is now viewed as a multi-faceted phenomenon, which is influenced by characteristics of the perpetrator, target, work group and organisation (Harvey et al. 2006; Heames and Harvey 2006), gaps still exist. Unlike the organisational or environmental perspective, which has been widely researched in the past decade, the group perspective has only recently been examined more closely. Indeed, the role of formal and informal groups and bystanders in the escalation or de-escalation of workplace bullying requires an in-depth research focus in the future. Social identity theory and social rules theory, as conceptually applied to workplace bullying by Ramsay et al. (2011), may guide 
researchers interested in the group level of analysis. In addition, the bystander perspective is an exciting area for the development of prevention and management strategies, as noted in this review. In overview, more research is required into group antecedents (both formal and informal groupings), as well as continued research into individual factors, especially with regard to perpetrators and bystanders, and organisational or environmental factors. Moreover, given that workplace bullying is accepted as a multi-faceted phenomenon, there is a need to examine the interaction between each of these levels, rather than continuing to explore them in isolation of each other.

Fourthly, as highlighted in this review, many of the deficiencies in the literature have consequences for the development of individual and organisational responses. Perhaps related to the lack of a comprehensive theory, research into the efficacy of interventions is at an early stage of development, with limited empirical analyses of formal initiatives (e.g., 'nobullying' policies) and informal processes (e.g., leadership development) available. Further research in particular is required into the usefulness of mediation, and contexts where it is most suitable (Jenkins 2011). Furthermore, the value of written policies associated with preventive and management interventions also requires further research attention, especially due to its overwhelming use in organisations as a measure to reduce or manage workplace bullying. For example, it would be helpful to better understand whether certain types of policies are most efficacious in enhancing staff awareness of bullying behaviours and expected organisational responses. In addition, professional development of staff needs to be far more evidenced-based then it currently is, suggesting extensive avenues for empirical research. Indeed, human resource management practitioners repeatedly call for evaluation studies to help inform staff training and development initiatives (Noe and Winkler 2012). However, despite some advancement in this area, the efficacy of many training and development interventions is not known and requires further research, with experimental and 
quasi-experimental research designs most useful in this regard. Likewise, comprehensive strategies for addressing workplace bullying, including the involvement of workplace climate and culture lack development and evaluation, although initial research demonstrates promise (see Keashly and Neuman 2009; Osatuke et al. 2009).

In conclusion, while this review has highlighted important advancements in the field, it has also identified gaps in our understanding of the phenomenon itself and its associated processes. An important contribution of this review is a new integrative model that captures the complexity of workplace bullying processes and provides a way forward for researchers and practitioners. 


\section{References}

Agervold, M. (2007). Bullying at work: A discussion of definitions and prevalence, based on an empirical study. Scandinavian Journal of Psychology, 48, pp. 161-172.

Agervold, M. (2009). The significance of organizational factors for the incidence of bullying. Scandinavian Journal of Psychology, 50, pp. 267-276.

Aquino, K. and Lamertz, K. (2004). A relational model of workplace victimization: Social roles and patterns of victimization in dyadic relationships. Journal of Applied Psychology, 89, pp. 1023-1034.

Ashkanasy, N. (2003). Emotions in organizations: A multi-level perspective. Multi-Level Issues in Organizational Behavior and Strategy, 2, pp. 9-54.

Ayoko, O. (2007). Communication openness, conflict events and reactions to conflict in culturally diverse workgroups. Cross Cultural Management: An International Journal, 14, pp. 105-124.

Ayoko, O., Callan, V. and Hartel, C. (2003). Workplace conflict, bullying, and counterproductive beahviors. The International Journal of Organizational Analysis, 11, pp. 283-301.

Baillien, E., De Cuyper, N. and De Witte, H. (2011a). Job autonomy and workload as antecedents of workplace bullying: A two-wave test of Karasek's Job Demand Control Model for targets and perpetrators. Journal of Occupational and Organizational Psychology, 84, pp. 191-208.

Baillien, E. and De Witte, H. (2009). Why is Organizational Change Related to Workplace Bullying? Role Conflict and Job Insecurity as Mediators. Economic and Industrial Democracy, 30, pp. 348-371.

Baillien, E., Neyens, I., De Witte, H. and De Cuyper, N. (2009). A qualitative study on the development of workplace bullying: Towards a three way model. Journal of Community \& Applied Social Psychology, 19, pp. 1-16.

Baillien, E., Rodríguez-Muñoz, A., De Witte, H., Notelaers. G. and Moreno-Jiménez, B. (2011b). The demand-control model and target's reports of bullying at work: A test within Spanish and Belgian blue-collar workers. European Journal of Work and Organizational Psychology, 20, pp. 157-177.

Banyard, V., Moynihan, M. and Plante, E. (2007). Sexual violence prevention through bystander education: An experimental evaluation. Journal of Community Psychology, 35, pp. 463-481.

Banyard, V., Plante, E. and Moynihan, M. (2004). Bystander Education: Bringing a broader community perspective to sexual violence prevention. Journal of Community Psychology, 32, pp. 61-79.

Baumeister, R., Smart, L. and Boden, J. (1996). Relation of threatened egotism to violence and aggression: The dark side of high self-esteem. Psychological Review, 103, pp. 533.

Beale, D. and Hoel, H. (2011). Workplace bullying and the employment relationship : Exploring questions of prevention, control and context. Work, Employment \& Society, 25, pp. 5-18.

Branch, S. (2008). You say Tomatoe and I say Tomato: Can we differentiate between workplace bullying and other counterproductive behaviours? International Journal of Organisational Behaviour, 13, pp. 4-17.

Branch, S., Ramsay, C. and Barker, M. (2007a). Managers in the firing line: Contributing factors to workplace bullying by staff - an interview study. Journal of Management \& Organization, 13, pp. 264-281. 
Branch, S., Ramsay, S. and Barker, M. (2007b). The bullied boss: A conceptual exploration of upwards bullying. In Glendon, A.I., Thompson, B.M. \& Myors, B. (eds.), Advances in organisational psychology. Bowen Hills, Qld: Australian Academic Press, pp. 93112.

Brotheridge, C. and Lee, R. (2010). Restless and confused emotional responses to workplace bullying in men and women. Career Development International, 15, pp. 687-707.

Caponecchia, C. and Wyatt, A. (2009). Distinguishing between workplace bullying, harassment and violence: A risk management approach. Journal of Occupational Health and Safety Australia and New Zealand, 25, pp. 439-449.

Clegg, S. (1993). Narrative, power and social theory. In Mumby, D. (ed.), Narrative and social control: Critical perspective. Newbury, CA: Sage Publications, pp. 15-45.

Cortina, L. (2008). Unseen injustice: Incivility as modern discrimination in organizations. Academy of Management Review, 33, pp. 55-75.

Coyne, I., Seigne, E. and Randall, P. (2000). Predicting workplace victim status from personality. European Journal of Work and Organizational Psychology, 9, pp. 335349.

D'Cruz, P. (2010). Identity disruptions and identity work: Understanding the impact of workplace bullying on targets International Journal of Organizational Behaviour, 15, pp. 36-52.

D'Cruz, P. and Noronha, E. (2010). Protecting my interests: HRM and targets' coping with workplace bullying. The Qualitative Report, 15, pp. 507-534.

D'Cruz, P. and Noronha, E. (2012). Clarifying My World: Identity Work in the Context of Workplace Bullying. The Qualitative Report, 17, pp. 1-29.

De Cuyper, N., Baillien, E. and De Witte, H. (2009). Job insecurity, perceived employability and targets' and perpetrators' experiences of workplace bullying. Work \& Stress, 23, pp. $206-224$.

de Wet, C. (2010). The reasons for and the impact of principal-on-teacher bullying on the victims' private and professional lives. Teaching and Teacher Education, 26 pp. 1450-1459.

Djurkovic, N., McCormack, D. and Casimir, G. (2008). Workplace bullying and intention to leave: The moderating effect of perceived organisational support. Human Resource Management Journal, 18, pp. 405-422.

Einarsen, S. (2000). Harassment and bullying at work: A review of the Scandinavian approach. Aggression and Violent Behavior, 5, pp. 379-401.

Einarsen, S., Hoel, H., Zapf, D. and Cooper, C. (2003). The concept of bullying at work: The European tradition. In Einarsen, S., Hoel, H., Zapf, D. \& Cooper, C. (eds.), Bullying and emotional abuse in the workplace: International perspectives in research and practice. London: Taylor \& Francis, pp. 1-30.

Einarsen, S., Hoel, H., Zapf, D. and Cooper, C. (2011). The concept of Bullying and Harassment at Work: The European Tradition. In Einarsen, S., Hoel, H., Zapf, D. \& Cooper, C. (eds.), Bullying and Harassment in the Workplace: Developments in Theory, Research, and Practice. 2nd ed. London: Taylor \& Francis Group, pp. 3-40.

Escartín, J., Zapf, D., Arrieta, C. and Rodríguez-Carballeira, A. (2011). Workers' perception of workplace bullying: A cross-cultural study. European Journal of Work and Organizational Psychology, 20, pp. 178-205.

Ferris, P. (2004). A preliminary typology of organisational response to allegations of workplace bullying: See no evil, hear no evil, speak no evil. British Journal of Guidance \& Counselling, 32, pp. 389-395. 
Fevre, R., Robinson, A., Jones, T. and Lewis, D. (2010). Researching Workplace Bullying: the benefits of taking an integrated approach. International Journal of Social Research Methodology, 13, pp. 71 - 85.

Folkman, S. and Moskowitz, J.T. (2000). Stress, positive emotion and coping. Current Directions in Psychological Science, 9, pp. 115-118.

Foucault, M. (1977). Discipline and punish: The birth of the prison Hammondsworth: Penguin.

Fox, S. and Stallworth, L. (2005). Racial/ethnic bullying: Exploring links between bullying and racism in the US workforce. Journal of Vocational Behavior, 66, pp. 438-456.

Fox, S. and Stallworth, L. (2009). Building a framework for two internal organizational approaches to resolving and preventing workplace bullying: Alternative dispute resolution and training. Consulting Psychology Journal: Practice and Research, 61, pp. 220-241.

French, J. and Raven, B. (1959). The bases of social power. In Cartwright, D. (ed.), Studies in social power. Ann Arbor: The University of Michigan, pp. pp. 150-167.

Fuller, J., Stanton, J., Fisher, G., Spitzmuller, C., Russell, S. and Smith, P. (2003). A lengthy look at the daily grind: Time series anlaysis of events, mood, stress, and satisfaction. Journal of Applied Psychology, 88, pp. 1019-1033.

Ghosh, R., Dierkes, S. and Falletta, S. (2011). Incivility spiral in mentoring relationships: Reconceptualizing negative mentoring as deviant workplace behavior. Advances in Developing Human Resources, 13, pp. 22-39.

Glasø, L., Matthiesen, S., Nielsen, M. and Einarsen, S. (2007). Do targets of workplace bullying portray a general victime personality profile? Scandinavian Journal of Psychology, 48, pp. 313-319.

Glas $\varnothing$, L., Vie, T., Holmdal, G. and Einarsen, S. (2011). An application of Affective Events Theory to workplace bullying: The role of emotions, trait anxiety, and trait anger. European Psychologist, 16, pp. 198-208.

Glomb, T. (2002). Workplace aggression: Antecedents, behavioral components, and consequences. Journal of Occupational Health Psychology, 7, pp. 20-36.

Grandey, A., Kern, J. and Frone, M. (2007). Verbal abuse from outsiders versus insiders: Comparing frequency, impact on emotional exhaustion, and the role of emotional labor. Journal of Occupational Health Psychology, 12, pp. 63-79.

Grzywacz, J. and Marks, N. (2000). Reconceptualizing the Work-Family Interface: An Ecological Perspective on the Correlates of Positive and Negative Spillover Between Work and Family. Journal of Occupational Health Psychology, 5, pp. 111-126.

Harvey, M.G., Heames, J.T., Richey, R.G. and Leonard, N. (2006). Bullying: From the playground to the boardroom. Journal of Leadership and Organizational Studies, 12, pp. 1-11.

Hauge, L., Skogstad, A. and Einarsen, S. (2009). Individual and situational predictors of workplace bullying: Why do perpetrators engage in the bullying of others? Work \& Stress, 23, pp. 349 - 358.

Heames, J. and Harvey, M. (2006). Workplace bullying: A cross-level assessment. Management Decision, 44, pp. 1214-1230.

Hershcovis, M.S. (2011). "Incivility, social undermining, bullying...oh my!": A call to reconcile constructs within workplace aggression research. Journal of Organizational Behavior, 32, pp. $499-519$.

Hess, J. (2000). Maintaining nonvoluntary relationships with disliked partners: An investigation into the use of distancing behaviors. Human Communication Research, 26, pp. 458-488. 
Hess, J. (2006). Distancing from problematic coworkers. In Harden Fritz, J. \& Omdahl, B. (eds.), Problematic relationships in the workplace. New York: Peter Lang, pp. 205232.

Hoel, H. and Cooper, C. (2000). Destructive conflict and bullying at work. Manchester, UK: School of Management, University of Manchester, Institute of Science and Technology.

Hoel, H. and Cooper, C. (2001). Origins of bullying: Theoretical frameworks for explaining workplace bullying. In Tehrani, N. (ed.), Building a culture of respect: Managing bullying at work. London: Taylor \& Francis, pp. 3-20.

Hoel, H. and Einarsen, S. (2010). Shortcomings of antibullying regulations: The case of Sweden. European Journal of Work and Organizational Psychology, 19, pp. 30 - 50.

Hoel, H., Sheehan, M., Cooper, C. and Einarsen, S. (2011). Organisational effects of workplace bullying. In Einarsen, S., Hoel, H., Zapf, D. \& Cooper, C. (eds.), Bullying and Harassment in the Workplace: Developments in Theory, Research, and Practice. 2nd ed. London: Taylor \& Francis Group, pp. 129-148.

Hoel, H., Zapf, D. and Cooper, C. (2002). Workplace bullying and stress. Historical and Current Perspectives on Stress and Health, 2, pp. 293-333.

Hogh, A., Mikkelsen, E. and Hansen, A. (2011). Individual consequences of workplace bullying/mobbing. In Einarsen, S., Hoel, H., Zapf, D. \& Cooper, C. (eds.), Bullying and Harassment in the Workplace: Developments in Theory, Research, and Practice. 2nd ed. London: Taylor \& Francis Group, pp. 107-128.

Hubert, A. and van Veldhoven, M. (2001). Risk sectors for undesirable behaviour and mobbing. European Journal of Work and Organizational Psychology, 10, pp. 415424.

Hutchinson, M., Vickers, M., Jackson, D. and Wilkes, L. (2006a). "Like wolves in a pack": Stories of predatory alliances of bullies in nursing. Journal of Management and Organisation, 12, pp. 235-251.

Hutchinson, M., Vickers, M., Jackson, D. and Wilkes, L. (2006b). Workplace bullying in nursing: towards a more critical organisational perspective. Nursing Inquiry, 13, pp. 118-126.

Ishiyama, F.I. (in press). A new psychoeducational approach to addressing and preventing prejudice and discrimination in a multicultural society: "Anti-discrimination Response Training" based on an active witnessing model. Journal of Tohoku Psychological Association, pp.

Jenkins, M. (2011). Practice Note: Is mediation suitable for complaints of workplace bullying? . Conflict Resolution Quarterly, 29, pp. 25-38.

Kanner, A., Coyne, J., Schaefer, C. and Lazarus, R. (1981). Comparison of two modes of stress measurement: daily hassles and uplifts versus major life events. Journal of Behavioral Medicine, 4, pp. 1-39.

Karasek, R.A. (1979). Job demands,job decision latitude, and mentalstrain: Implications for job redesign. Administrative Science Quarterly, 24, pp. 285-308.

Katz, J. (1995). Reconstructing masculinity in the locker room: The Mentors in Violence Prevention Project. Harvard Educational Review, 65, pp. 163-174.

Keashly, L. and Harvey, S. (2006). Workplace emotional abuse. In Kelloway, E., Barling, J. \& Hurrell Jr., J. (eds.), Handbook of workplace violence. Thousand Oaks: SAGE Publications, pp. 95-120.

Keashly, L. and Jagatic, K. (2011). North American Perspectives on Hostile Behaviors and Bullying at Work. In Einarsen, S., Hoel, H., Zapf, D. \& Cooper, C. (eds.), Bullying and Harassment in the Workplace: Developments in Theory, Research, and Practice. 2nd ed. London: Taylor \& Francis Group, pp. 41-71. 
Keashly, L. and Neuman, J. (2009). Building constructive communication climate: The U.S. Department of Veterans Affairs Workplace Stress and Aggression Project. In LutgenSandvik, P. \& Sypher, B. (eds.), The destructive side of organizational communication: Processes, consequences and constructive ways of organizing. New York: Routledge/LEA, pp. 339-362.

Kivimaki, M., Elovainio, M. and Vahtera, J. (2000). Workplace bullying and sickness absence in hospital staff. Occupational and Environmental Medicine, 57, pp. 656-660.

La Van, H. and Martin, M. (2008). Bullying in the U.S. Workplace: Normative and ProcessOriented Ethical Approaches. Journal of Business Ethics, 83, pp. 147-165.

Lamertz, K. and Aquino, K. (2004). Social power, social status and perceptual similarity of workplace victimization: A social network analysis of stratification. Human Relations, 57, pp. 795-822.

Lee, F. (1997). When the going gets tough, do the tough ask for help? Help seeking and power motivation in organizations. Organizational Behavior and Human Decision Processes, 72, pp. 336-363.

Lee, R. and Brotheridge, C. (2006). When prey turns predatory: Workplace Bullying as a predictor of counteraggressio/bullying, coping and well-being. European Journal of Work and Organizational Psychology, 15, pp. 352-377.

Lewis, D. (2004). Bullying at work: The impact of shame among university and college lecturers. British Journal of Guidance \& Counselling, 32, pp. 281-299.

Lewis, D. and Gunn, R. (2007). Workplace Bullying in the Public Sector: Understanding the racial dimension. Public Administration, 83, pp. 641-665.

Lewis, S. and Orford, J. (2005). Women's experiences of workplace bullying: Changes in social relationships. Journal of Community \& Applied Social Psychology, 15, pp. 2947.

Leymann, H. (1996). The content and development of mobbing at work. European Journal of Work and Organizational Psychology, 5, pp. 165-184.

Leymann, H. and Gustafsson, A. (1996). Mobbing at work and the development of Posttraumatic Stress disorders. European Journal of Work and Organizational Psychology, 5, pp. 251-275.

Lim, S., Cortina, L. and Magley, V. (2008). Personal and wrkgroup incivility: Impact on work and health outcomes. Journal of Applied Psychology, 93, pp. 95-107.

Lind, K., Glas $\varnothing$, L., Pallesen, S. and Einarsen, S. (2009). Personality profiles among targets and nontargets of workplace bullying. European Psychologist, 14, pp. 231-237.

Lutgen-Sandvik, P. (2006). Take this job and ... :Quitting and other forms of resistance to workplace bullying. Communication Monographs, 73, pp. 406-433.

Lutgen-Sandvik, P. (2008). Intensive remedial identity work: Responses to workplace bullying trauma and stigmatization. Organization, 15, pp. 97-119.

Magley, V., Hulin, C., Fitzgerald, L. and DeNardo, M. (1999). Outcomes of self-labeling sexual harassment. Journal of Applied Psychology, 84, pp. 390-402.

Matthiesen, S., Aasen, E., Holst, G., Wie, K. and Einarsen, S. (2003). The escalation of conflict: a case study of bullying at work. International Journal of Management and Decision Making, 4, pp. 96-112.

Matthiesen, S. and Einarsen, S. (2004). Psychiatric distress and symptoms of PTSD among victims of bullying at work. British Journal of Guidance \& Counselling, 32, pp. 335356.

Matthiesen, S. and Einarsen, S. (2007). Perpetrators and targets of bullying at work: Role stress and individual differences. Violence and Victims, 22, pp. 735-753. 
Mayhew, C., McCarthy, P., Chappell, D., Quinlan, M., Barker, M. and Sheehan, M. (2004). Measuring the extent of impact from occupational violence and bullying on traumatised workers. Employee Responsibilities and Rights Journal, 16, pp. 117-134.

McCarthy, P. and Barker, M. (2000). Workplace bullying risk audit. The Journal of Occupational Health and Safety - Australia and New Zealand, 16, pp. 409-418.

McCarthy, P., Henderson, M., Sheehan, M. and Barker, M. (2002). Workplace bullying: Its management and prevention. Australian Master OHS and Environment Guide 2003. Sydney: CCH Australia Limited, pp. 519-546.

McCarthy, P. and Mayhew, C. (2004). Safeguarding the organization against violence and bullying New York: Palgrave MacMillan.

McCarthy, P., Sheehan, M. and Kearns, D. (1995). Managerial styles and their effects on employees' health and well-being in organisations undergoing restructuring Brisbane: School of Organisational Behaviour \& Human Resource Management.

Mikkelsen, E. and Einarsen, S. (2002). Basic assumptions and symptoms of post-traumatic stress among victims of bullying at work. European Journal of Work and Organizational Psychology, 11, pp. 87-111.

Miller, L. (1997). Not just weapons of the weak: Gender harassment as a form of protest for army men. Social Psychology Quarterly, 60, pp. 32-51.

Namie, G. (2003). Workplace bullying: Escalated incivility. Ivey Business Journal, 68, pp. 16.

Namie, G. and Lutgen-Sandvik, P. (2010). Active and passive accomplices: The communal character of workplace bullying. International Journal of Communication, 4, pp. 343373.

Niedhammer, I., David, S., Degioanni, S. and 143 occupational physicians (2006). Association between workplace bullying and depressive symptoms in the French working population. Journal of Psychosomatic Research, 61, pp. 251-259.

Nielsen, M., Matthiesen, S. and Einarsen, S. (2008). Sense of Coherence as a Protective Mechanism Among Targets of Workplace Bullying. Journal of Occupational Health Psychology, 13, pp. 128-136.

Nielsen, M., Notelaers, G. and Einarsen, S. (2011). Measuring exposure to workplace bullying. In Einarsen, S., Hoel, H., Zapf, D. \& Cooper, C. (eds.), Bullying and Harassment in the Workplace: Developments in Theory, Research, and Practice. 2nd ed. London: Taylor \& Francis Group, pp. 149-174.

Noe, R. and Winkler, C. (2012). Training \& Development: Learning for Sustainable Managment Sydney: McGraw Hill.

O' Moore, M., Seigne, E., McGuire, L. and Smith, M. (1998). Victims of bullying at work in Ireland. The Journal of Occupational Health and Safety - Australia and New Zealand, 14, pp. 569-574.

Olweus, D. (1978). Aggression in the schools : bullies and whipping boys New York: Wiley.

Olweus, D. (1993). Bullying at school: What we know and what we can do Cambridge, MA: Blackwell Publishers.

Osatuke, K., Moore, S., Ward, C., Dyrenforth, s. and Belton, L. (2009). Civility, respect, engagement in the workforce (CREW): Nationwide organization development intervention at Veterans Health Administration. The Journal of Applied Behavioral Schience, 45, pp. 384-410.

Parzefall, M.-R. and Salin, D. (2010). Perceptions of and reactions to workplace bullying: A social exchange perspective. Human Relations, 63, pp. 761-780.

Privitera, C. and Campbell, M. (2009). Cyberbullying : the new face of workplace bullying? CyberPsychology and Behavior, 12, pp. 395-400. 
Quine, L. (1999). Workplace bullying in NHS community trust: Staff questionnaire survey. British Medical Journal, 318, pp. 228-232.

Ramsay, S., Troth, A. and Branch, S. (2011). Workplace bullying through the lens of social psychology: A group level Analysis. Journal of Occupational and Organizational Psychology, 84, pp. 799-816.

Raven, B. (1993). The bases of power: origins and recent developments. Journal of Social Issues, 49, pp. 227-242.

Rayner, C. (1997). The incidence of workplace bullying. Journal of Community \& Applied Social Psychology, 7, pp. 199-208.

Rayner, C. (1999). From research to implementation: Finding leverage for prevention. International Journal of Manpower, 20, pp. 28-38.

Rayner, C., Hoel, H. and Cooper, C. (2002). Workplace Bullying: What we know, who is to blame, and what can we do? London: Taylor \& Francis.

Rayner, C. and Lewis, D. (2011). Managing workplace bullying: The role of policies. In Einarsen, S., Hoel, H., Zapf, D. \& Cooper, C. (eds.), Bullying and Harassment in the Workplace: Developments in Theory, Research, and Practice. 2nd ed. London: Taylor \& Francis Group, pp. 327-340.

Reio, T. and Ghosh, R. (2009). Antecedents and outcomes of workplace incivility: Implications for human resource development research and practice. . Human Resource Development Quarterly, 20, pp. 237-264.

Roscigno, V., Lopez, S. and Hodson, R. (2009). Supervisory bullying, status inequalities and organizational context. Social Forces, 87, pp. 1561-1589.

Saam, N. (2010). Interventions in workplace bullying: A multilevel approach. European Journal of Work and Organizational Psychology, 19, pp. 51-75.

Salin, D. (2003a). Bullying and organisational politics in competitive and rapidly changing work environments. International Journal of Management and Decision Making, 4, pp. 35-46.

Salin, D. (2003b). Ways of explaining workplace bullying: A review of enabling, motivating, and precipitating structures and processes in the work environment. Human Relations, 56, pp. 1213-1232.

Salin, D. (2008). The prevention of workplace bullying as a question of human resource management: Measures adopted and underlying organizational factors. Scandinavian Journal of Management, 24, pp. 221-231.

Salin, D. (2009). Organisational responses to workplace harassment: An exploratory study. Personnel Review, 38, pp. 26-44.

Salin, D. (2011). The Significance of Gender for Third Parties' Perceptions of Negative Interpersonal Behaviour: Labelling and Explaining Negative Acts. Gender, Work, and Organization, 18, pp. 571-591.

Salin, D. and Hoel, H. (2011). Organisational causes of workplace bullying. In Einarsen, S., Hoel, H., Zapf, D. \& Cooper, C. (eds.), Bullying and Harassment in the Workplace: Developments in Theory, Research, and Practice. 2nd ed. London: Taylor \& Francis Group, pp. 227-244.

Saunders, P., Huynh, A. and Goodman-Delahunty, J. (2007). Defining workplace bullying behaviour professional lay definitions of workplace bullying. International Journal of Law and Psychiatry, 30, pp. 340-354.

Schat, A., Frone, M. and Kelloway, E. (2006). Prevelence of workplace aggression in the US workforce: Findings from a national study. In Kelloway, E., Barling, J. \& Hurrell Jr., J. (eds.), Handbook of workplace violence. Thousand Oasks, CA: Sage, pp. 47-90. 
Shallcross, L., Ramsay, S. and Barker, M. (2010). A proactive response to the mobbing problem: A guide for HR managers. New Zealand Journal of Human Resources Management, 10, pp. 27-37.

Shannon, C., Rospenda, K. and Richman, J. (2007). Workplace harassment patterning, gender, and utilization of professional services: Findings from a US national study. Social Science \& Medicine, 64, pp. 1178-1191.

Sheehan, M., McCarthy, P., Barker, M. and Henderson, M. (2001). A model for assessing the impacts and costs of workplace bullying. Standing Conference on Organizational Symbolism (SCOS). Trinity College Dublin.

Sliter, M., Jex, S., Wolford, K. and McInnerney, J. (2010). How rude! Emotional labor as a mediator between customer incivility and employee outcomes. Journal of Occupational Health Psychology, 15, pp. 468-481.

Tehrani, N. (2003). Counselling and rehabilitating employees involved with bullying. In Einarsen, S., Hoel, H., Zapf, D. \& Cooper, C. (eds.), Bullying and emotional abuse in the workplace: International perspectives in research and practice. London: Taylor and Francis, pp. 270-284.

Tehrani, N. (2004). Bullying: A source of chronic post traumatic stress? British Journal of Guidance \& Counselling, 32, pp. 357-366.

Vartia, M., Korppoo, L., Fallenius, S. and Mattila, M. (2003). Workplace bullying: The role of occupational health services. In Einarsen, S., Hoel, H., Zapf, D. \& Cooper, C. (eds.), Bullying and emotional abuse in the workplace: International perspectives in research and practice. London: Taylor and Francis, pp. 285-298.

Weiss, H. and Cropanzano, R. (1996). Affective Events Theory: A theoretical discussion of the structure, causes and consequences of affective experiences at work. In Staw, B. \& Cummings, L. (eds.), Research in Organizational Behavior. Greenwich, CT: JAI Press, pp. 1-74.

Wheeler, A.R., Halbesleben, J.R.B. and Shanine, K. (2010). Eating their cake and everyone else's cake, too: Resources as the main ingredient to workplace bullying. Business Horizons, 53, pp. 553-560.

Zapf, D. (1999). Organisational, work group related and personal causes of mobbing/bullying at work. International Journal of Manpower, 20, pp. 70-85.

Zapf, D. and Einarsen, S. (2011). Individual antecedents of bullying: Victims and Perpetrators. In Einarsen, S., Hoel, H., Zapf, D. \& Cooper, C. (eds.), Bullying and Harassment in the Workplace: Developments in Theory, Research, and Practice. 2nd ed. London: Taylor \& Francis Group, pp. 177-200.

Zapf, D., Escartin, J., Einarsen, S., Hoel, H. and Vartia, M. (2011). Empirical findings on prevalence and risk groups of bullying in the workplace. In Einarsen, S., Hoel, H., Zapf, D. \& Cooper, C. (eds.), Bullying and Harassment in the Workplace:

Developments in Theory, Research, and Practice. 2nd ed. London: Taylor \& Francis Group, pp. 75-106.

Zapf, D. and Gross, C. (2001). Conflict escalation and coping with workplace bullying: A replication and extension. European Journal of Work and Organizational Psychology, 10, pp. 497-522. 